\title{
Intercultural adaptation in the work area among professional Indonesian workers in Malaysia
}

\author{
Nani Haryanih \\ Cultural and Media Studies Universitas Gadjah Mada, Jl. Teknika Utara, Pogung, Sleman, \\ Yogyakarta, Indonesia 55281 \\ e-mail: naniharyanih@gmail.com
}

\begin{abstract}
As a consequence, in the era of globalization, the migration of workers and economic flows has grown rapidly over the last decade and has become a phenomenon. Many migrant workers from abroad are employed in certain countries which lack the resources of labor. One of the countries whose economic development depends on migrant workers is Malaysia. Malaysia's dependence on migrant workers is quite high, especially for unskilled and semi-skilled works. However, in addition to skilled/ semi-skilled workers, there are many skilled workers working in Malaysia. They usually work in areas which require expertise or special skills, one of them is in the IT (Information Technology) sector. The purpose of this paper is to study the process of inter-cultural adaptation that occurs to Indonesian professional workers currently working in Malaysia, especially the adaptation process that occurs in their multicultural workplace. This study uses a qualitative methodology of 10 Indonesian professional workers in Malaysia, in particular working on Nokia Siemens Networks Sdn. Bhd., Malaysia. By conducting research with the qualitative method, the result is the cultural diversity in Malaysia and in the work area of respondents, does not seem to be a big problem for them.
\end{abstract}

\section{Keywords}

Indonesian workers, intercultural adaptation, migrant workers, professional workers, skilled-workers

\section{Introduction}

Citation: Haryanih, N. (2018). Intercultural adaptation in the work area among professional Indonesian workers in Malaysia. In M. Amini, M. Yusuf, \& V. I. Yulianto. (Eds.), UGM Digital Press Social Sciences and Humanities: Vol. 1. Proceeding of the 2nd International Conference on South East Asia Studies, (pp. 77-85).

Published: October, 2018
What will happen if we as an individual are born and raised in a culture and then settled and live in another new culture? How do we overcome the uncertainty in the new environment? Why do some of us look easier in adapting, while some others look hard to adapt in the new environment?

Studies on inter-cultural adaptation have long been a concern of some scholars from various fields of study, such as anthropology, communication, psychology, sociology, and sociolinguistics. Many books have been focused on the study of intercultural among these cultures, such as the old famous book titled Acculturation (Padilla, 1980) which consists of several articles containing the findings of the psychological experience of immigrants. The second book is Cross Cultural Adaptation (Y. Kim \& Gudykunts, 1987), a multidisciplinary 
anthology that contains concepts and findings on intercultural adaptation studies viewed from a point of view/ knowledge perspective of Anthropology, Communication, and Social-sychology. All of these books have been able to encourage the study of intercultural adaptation towards the integration of various perspectives in explaining the intercultural adaptation phenomenon.

Intercultural adaptation processes will be found in cases of mobilization or human migration, both migrations that occur in one country or international migration. In the migration process, immigrants do not only bring their physical form, but they also carry some of their lifestyles, their culture, and the values and norms that originate from their origin to their new place. In international migration, there will be a situation in which the new comers will have to overcome a cultural change. Generally, the motivation to adapt really depends on whether they should stay in a new place or not. For short-term sojourners, perhaps they will not feel the need to deeply study the cultures in their new place. Usually the reasons for immigrants to adapt are often pragmatic and specific - such as for a holiday, for education, or solely for raising prestige only. For example, foreign students can adapt to new environments if they are more interacting with local students.

In the era of globalization this level of dependence on relations among the existing countries is also increasing, there is no single country in the world that can fulfill all the needs for its own nation. The intensity of the current globalization also brings impact on the flow of mobilization or human migration from one country to another. Such migration or mobilization has the purpose of attending education (for foreign students), to conduct business transactions (for business agents), for vacation (for travelers), to get a better life (for refugees and migrant workers), and so on.

\subsection{Cultural/Culture Shock}

In conducting intercultural adaptation the possibility of cultural/culture shock will always exist. Cultural/ culture shock can be seen from the perspective of psychopsychology (sociocultural). This cultural shock generally is conceptualized (Oberg, 1954, 1960) that arises as a result of the rise of tension and anxiety in the process of interacting with new cultures and also the consequences of the emergence of loss of sense, confusion and impotence resulting from the loss of cultural cues and social rules which normally accepted.

Although, as we have seen so far, treatment-side models of cultural shock are more dominant, such as reactions that emerge from the psychological and cognitive aspects, however, the implications of the existence of a real cultural shock are wider. The true cultural shock originates, either from the rejection of a new culture, as well as a sense of loss of a previously known culture (Rhinesmith, 1985).

In the process of adaptation, there will be a cultural shock. Cultural shock is a great deal of experience gained through a number of trigger factors that occur as we interact with different cultures with the original culture. Common cultural shocks happen to immigrants (such as overseas students and refugees (Dodge, 1990), business actors or agents whom are doing overseas assignments (Walton, 1990); people working in their own societies and cultures (such as, a business institution that is reorganizing its organization (Knobel, 1988); a group of human populations who are facing the rapid technological development and social change (Toffler, 1970); then staff, clients, societies found in other institutions). Reactions to cultural shock can be a trigger for a person's psychological crisis and social dysfunction when cultural differences exist in the way of interaction. This is because the community nowadays is more multicultural (Schwartz \& Exter, 1989).

The circumstances that trigger the emergence of cultural shock and reaction emerging from each individual depends on a variety of factors, including past experiences when interacting and adapting to other cultures; the level of cultural differences between the person and the host culture; level of preparation in dealing with cultural differences; social support networks; and the psychological characteristics of a person (Furnham \& Bochner, 1986).

The level of effectiveness in dealing with the occurrence of a person's cultural shock is determined by a number of factors, including understanding the natural condition that causes a cultural shock, a strategy used to improve the process of intercultural adaptation and communication, and the degree of effectiveness of the cross-cultural training program based on the principles of social learning principles combined with 2 (two) approaches namely cognitive and behavioral approach (Black \& Mendenhall, 1990).

Cultural shock occurs when in cognitive (mind) has excessive expectations of something, but in reality one does not have enough ability to adapt to the emerging cultural differences. Therefore, in the pursuit of a solution culture, the best solution is to use a social learning approach where an individual's attitude and cognitive information can be integrated into behavioral transformations (Winkelman, 2002). 
Immigrants and sojourners are agents that need the ability to adapt in new environments, and during the adaptation process they will certainly find some obstacles that will challenge them. If they can not cope with the challenges, then it is likely they will experience a cultural shock.

\subsection{Theoretical Framework}

The results of the study conducted by Duronto, et.al. (2005) indicate that the Concerns Management or Uncertainty Theory can be used to examine the link between anxiety or uncertainty with the avoidance that occurs in interpersonal and intercultural communication. The writer examines that there is a connection between the communication that occurs between different strangers of culture with anxiety and uncertainty. However, anxiety and uncertainty are not related to communication between strangers who have cultural similarities. The findings in this journal article support part of the Management Concerns and Uncertainties.

This theory was explained by William Gudykunst (1985). This theory focuses on cross-cultural communication between individuals from one group to another. This situation makes the individual concerned with anxiety and uncertainty. This happens because when we meet someone for the first time (stranger), we do not know the feelings and the behavior of the individual. To help us understand this theory, we need to clearly distinguish between concepts of concern/ anxiety and uncertainty.

According to Gudykunst, uncertainty is in cognitive form or in our minds. Uncertainty in this situation makes us uncertain about our ability to predict the outcomes of our meetings with people we have not known from different cultures. The uncertainty also makes us unprepared to plan how to act when meeting the person concerned. Anxiety reflects the attitude of expectation. It is an uncomfortable, stressful and anxious feeling about what might happen when we meet strangers who have not known us. The concerns / anxiety also reflected the fear of the difference between the people involved and the communication with the person concerned does not achieve the desired satisfaction. Gudykunst (1995) has given three factors, namely motivation factor, knowledge factor, and skill factor that influence anxiety and uncertainty which causes communication effectiveness.

Given the Uncertainty Reduction Theory proposed by Berger (1987) that is, for every new introduction, the main thing is to reduce uncertainty. If we are more confident about the individual, it will be easier to communicate. It is important that we take the story, take care and respect about what we say and do so that we do not offend others. The way we take the story or pay attention depends on how much we care about our relationship and the acceptance of the group to us.

Meanwhile, Black \& Mendenhall (1990) state that the level of effectiveness in dealing with the occurrence of a person's cultural shock is determined by several factors, including understanding the natural conditions that cause a cultural shock, a strategy used to improve the process of intercultural adaptation and communication, As well as improving the effectiveness of cross-cultural training programs should be based on the principles of social learning principles combined with 2 (two) approaches: cognitive and behavioral approaches. Cultural shock occurs when in cognitive (mind) we have excessive expectations of something, but in the reality we do not have enough ability to adapt to the emerging cultural differences. Therefore, in the pursuit of a culture of solving the preferred solution is to use a social learning approach where an individual's attitude and cognitive information can be integrated into behavioral transformations (Winkelman, 2002).

The Social Learning Theory is the theory that results from a combination of behavioral and cognitive theory. Bandura (1977) states that we can learn by observing others; Social Learning Theory is the theory of human behavior, in particular to explain the impact of mass media. This theory has three stages: attention, retention, and motivation.

However, Young Yun Kim (1988) states that in studying the process of intercultural adaptation, he proposes to use a theoretical approach based on a general system perspective that sees that individuals, both immigrants and sojourners, will interact with open systems interacting in adapting, local interconnectedness where they live, with their native cultures. Through this open-system perspective, which focuses on communication, this theory combines the existence of cross-cultural adaptation concepts that relate to empirical findings in human sciences studies, including anthropological studies, communication, sociolinguistics, social psychology, sociology, psychiatry, and other related science studies. In addition, this theory should also seek to develop general descriptions and explain the cross-cultural adaptation process, based on the characteristics or unique experiences of each individual and the circumstances under which it applies. 


\subsection{Problems of The Study}

The studies on the process of adaptation of immigrants and sojourners have been widely practiced by scholars from various scientific studies in human sciences, including anthropology, communication, sociolinguistics, social psychology, sociology, psychiatry, and other related science studies, as it is considered interesting, will always develop, and empirical.

Therefore, as a researcher, the writer feels that the study of the process of adaptation in the workplace among Indonesian professional workers in Malaysia is quite interesting to be studied, as many Indonesians are employed in Malaysia, either as a labor force or labor, as well as professional ones. The writer sees this because the Indonesian-Malaysian culture is almost identical, but not the same, as it is also due to geographical approach.

Professional Indonesian workers have the capability to interact and adapt to the diversity of cultures inherent in their multiethnics and multinational workplaces, as they have good skills in foreign language, which is English, and even more so among them have had previous experience in interacting with strangers who have many cultural differences. Also, they are also likely to have gathered a lot of information on their new work area and the countries where they will work. With all this, they should not have had a significant barrier to adapting, especially if they only work in Malaysia where both in terms of culture and climate and the weather (environment) have no significant difference.

But is that true? Do with all the advantages and skills they have will make them easier to adapt to Malaysia? Do they not find any challenges in their adaptation process, especially in the workplace? Therefore, the writer is keen to know the adaptation process in the workplace among Indonesian professional workers currently working in Malaysia.

Therefore, as a researcher, the writer thinks that the study of the process of adaptation in the workplace among Indonesian professional workers in Malaysia is quite interesting to be studied, as many Indonesians are employed in Malaysia, either as a labor force or labor, as well as as a professional force. Researchers see this because the Indonesian-Malaysian culture is almost identical, but not the same, as it is also due to geographical approach.

The writer wants to know whether the existence of cultures between Indonesia and Malaysia that is almost similar, but not the same, will make it easier for Indonesian working professionals working in Malaysia to adapt to their environment or work area? The writer also wants to know whether some of the cultural differences that exist will distract their effectiveness in working, also what do they do to adapt or adapt to a new working environment?

\subsection{Objective of The Study}

The objectives of the study are:

1. Are professional Indonesian workers who have previously had experience working overseas, will have the easier to adapt to a new working environment (in Malaysia)?

2. Have they ever experienced a cultural shock during their stay in Malaysia?

3. What do they do to be able to adapt to the diversity of the culture that exists in their workplace now?

\subsection{Scope of The Study}

While the writer is in Malaysia, she realises that besides Indonesian workers become laborers, it is obvious that many Indonesian professional workers are also in Malaysia, they are widely spread in several foreignowned (multinational) companies in Malaysia, though many are also working in several major Malaysian companies, such as Proton, MAS, and so on.

Meanwhile, as the Indonesian people in Malaysia are only considered to be employed in dangerous, dirty, and low-paid workplaces, with the increasing number of Indonesian professional workers in Malaysia, may sooner or later, be able to erase the Malaysians' negative stereotype towards them all this time. Professional Indonesian workers as well as Malaysian students in Malaysia, will gradually build a positive image of Indonesia among Malaysians.

When there has been so much news about the behavior of TKI (Indonesian Labors) in Malaysia that behave negatively with its motives, in this case the writer also analyzes it from their unpreparedness (the Indonesian labors) in adapting to the new environment in Malaysia. Their incompatibility may be in terms of mastery of the Malay language, especially in English. In addition, they also lack real information about 
the situation in Malaysia, such as in terms of culture, association, law, and so on. Thus, they may experience cultural / culture shock.

Then what about Indonesian professional workers in Malaysia? The writer sess that professional workers have more preparation both in terms of cognition and thinking, as generally work in Malaysia, they have gained enough information about the country, such as its culture, socialization, law, and so on. In addition, they have also had previous experience in a multinational working environment with ethnic and cultural diversity.

Then with all the advantages and skills they have, will they ensure they will be more adaptable to their work in Malaysia? That is why the writer is keen to analyze it.

\section{Methods}

In this study, the writer used qualitative method on 10 (ten) Indonesian professional workers currently employed at Nokia Siemens Networks Sdn.Bhd., Malaysia. Qualitative method is done with them by phone; this is done as the writer is unable to meet with respondents directly due to the occupancy of the respondents. With qualitative method, the writer is able to obtain more information from respondents about the situation of their work area.

Number of samples for this qualitative method are 10 (ten) Indonesian professional workers, all of them have professions as engineers at Nokia Siemens Networks, Sdn. Bhd., Malaysia. Respondents aged between 27 and 33 years old. All male respondents reside in Damansara, Sri Petaling, Bukit Jalil and KLCC (Selangor).

For the level of education, 10 (ten) respondents, 1 (one) diploma-educated, 4 (four) persons with a first degree, and the remaining 5 (five) master degrees. According to work experience, out of 10 (ten) respondents, 4 (four) people had previously worked abroad experience (other than Indonesia), foreign countries that have been their workplace, among others, Germany, Australia, and Kenya. In writing this paper report, the writer will only write the initials of the respondents' names, arranged alphabetically. The initials used are letters from A to Alphabet J (10 respondents).

Table 1 Sample of the Study

\begin{tabular}{|l|l|}
\hline Number of Respondents & 10 (ten) people \\
\hline Respondent's residence & $\begin{array}{l}\text { Around of area Damansara, Sri Petaling, } \\
\text { Bukit Jalil, and KLCC (Selangor, Malaysia) }\end{array}$ \\
\hline Age & Between 27-33 years old \\
\hline Gender & All male \\
\hline
\end{tabular}

Table 2 Respondents' level of education

\begin{tabular}{|l|l|}
\hline Diploma: & 1 (one) person \\
\hline First degree: & 4 (four) persons \\
\hline Master degree: & 5 (five) persons \\
\hline
\end{tabular}

Table 3 Works Experiences in Overseas (Other than in Indonesia)

\begin{tabular}{|l|l|}
\hline Non overseas: & 6 (six) persons \\
\hline Overseas: & 4 (four) persons \\
\hline
\end{tabular}

\section{Results of The Study}

Here are some questions asked by the writer to the respondents:

1. When you first came to Malaysia, did you feel that there is a different culture between Indonesia and Malaysia?

2. According to you, what is the difference between existing cultures in Indonesia and Malaysia? 
3. In your work area, are you more interacting and communicating?

4. In your work area, what languages do you use often?

5. What do you think is the difference in working culture when you work in Indonesia with a work culture at your current job (Malaysia)?

6. Have you ever experienced cultural shock during your stay in Malaysia?

7. Have you ever experienced miscommunication / misunderstanding with people of different cultures where you work now?

8. Are you experiencing difficulties in adapting to the diversity of existing cultures in your work area now?

\subsection{Objective of Analysis 1}

"Are Indonesian professional workers who have previously had experience working overseas, will have better accessibility in adapting to a new working environment (in Malaysia)?"

As out of 10 (ten) respondents, there are only 4 (one) who have had work experience outside of other countries, besides in Indonesia and Malaysia. The four respondents are: B, Mr. C, Mr. D, and Mr. I.

However, it turns out that after the writer conducted an interview with the four men and asked if they were more adaptable to the new environment (in Malaysia), the result was good. B and Mr. C did not find any problems in interacting and adapting to a new environment.

But on Mr. D and Mr. I, appareantly they both stated sometimes they found some difficulties / distress, as stated by Mr. D.

"The main obstacle is only in interacting with the people from Germany who are there to come to the project, where the way they work is very different from the way Asian people work."

According to Mr. D, common problems at work with different cultures are: the way to communicate especially in terms of job delegation, they think they know everything (especially people from Germany), and they sometimes like not being honest about their actual work ability.

For Mr. I, he stated that sometimes the problem in the new workplace is just a bit misunderstanding.

From the above answers, the writer finds that in general, respondents find no difficulty in adapting to a new work environment (in Malaysia), both for those who have had experience working outside of other countries or who have never been. The writer sees this as they are familiar with interacting with foreigners and as long as their interactions are mostly related to the job, so if there is a problem, it may be just a matter related to the job alone.

From the respondents' answers, they did not find any problems related to local workers (Malaysians) this happened because in the project there were only 3 (three) Malaysians who worked as an engineer, the remaining workers were foreigners, Indonesians, people from India, Europe, Russia, and China.

\subsection{Objective of Analysis 2}

"Have they ever experienced a cultural shock while in Malaysia?"

For this question, the answers given by the respondents are very diverse, such as:

Mr. A: "No, maybe only little bit, for example is about the people in Malaysia habits on the highway, they don't usually honk the horn."

Mr. B: "Malaysian language in oral much different than Indonesian, they are many vocabularies that soundly funny but usually I used English as main language in work area."

Mr. C: "About the work habits, I think there are not so much differences."

Mr. D: "About the foods, I think Malaysian foods are have much influences from Thai Foods and Indian also Chinese. sometimes I feel weird with the taste, but for a little bit getting used to."

Mr. E: "I think Malaysian government is more efficient in doing some procedures and administration for their people and also foreigners, for example much easy and cheap to have driving lisence in here as long that we already have driving license before in Indonesia."

Mr. F: "People in Malaysia are more casual in wearing their clothes, especially when their going to the mall."

Mr. G: "Many foreign workers in Malaysia. Indigenous Malaysians do not want to do rough or humble jobs such as cleaning service so that many bring in foreign workers from outside the country such as Indonesia, Bangladesh, India, Nepal, and so on." 
Mr. H: "Although Bahasa Malaysia is the main language of the country, but English is more commonly used primarily for non-Malay ethnicity who speak with other ethnicity other than Malaysia, that is way I used to speak in English with them."

Mr. I: "Many Indonesian cultural products are quite salable in Malaysia such as songs from Indonesian singers who played in many radio stations in Malaysia and Indonesian soap operas are also pretty much in play on national television in Malaysia, so much like I lived in Indonesia"

Mr. A: "Before I came to Malaysia, I searched a lot about the cost of living there, the rent of the apartment or the house, the law there, the food, the public transportation, etc. So, I tried to learn and adjust so as not to be too shocked."

For this question, the writer discovers that none of the respondents had ever experienced a cultural shock during their stay in Malaysia. The writer assesses that the causes are:

1. There is not much cultural differences between Indonesia and Malaysia, it can be said in some respects that the cultures of both countries are very similar, making it easier for Indonesians to adapt in Malaysia. In addition, there are many Indonesians in Malaysia, thus, they feel that there is no significant difference.

2. These professional workers have generally sought out a variety of information in advance, relating to life in Malaysia, such as food, law, and so forth.

3. In terms of language and communication, they usually use English to do this to avoid miscommunication / misunderstanding in the work area.

\subsection{Objective of Analysis 3}

"What do they do to be able to adapt to the diversity of cultures that exist in their work area?"

For this question, the answers given by the respondents are very diverse, such as:

Mr. A: "Trying to join and talk with them."

Mr. B: "Trying to understand their culture."

Mr. C : "Behave and act normal."

Mr. D: "Changing the habit, always saying "yes", Do not think your opponent understand sully about the the talk (the conversation), always checking, and trying to avoid the people who always make trouble."

Mr. E : "Be as it is."

Mr. F : "Learning other cultures."

Mr. G: "Be polite only, try to be low profile, find out their culture, and most importantly speak good English."

Mr. H: "Trying to understand their culture."

Mr. I : "Trying to mingle with them."

Mr. A: "A lot of observing, watching and listening before acting, and finding out by discussing with others."

The diversity of answers given by the respondents in this question can actually be summarized to adapt to the diversity of cultures in their work environment, they are trying more to understand the differences by studying or learning other cultures, trying to mingle (interacting) with other cultures, and most important to them is to master the English language, as they interact with people from different countries, languages, and races, as with German, Polish, Indian, Romania, Austria, and Pakistan. Also for them, to mingle or get contact with people from various countries and races, they have been familiar with them as they worked in previous workplaces, such as in Nokia Siemens Networks (NSN) Indonesia and NSN in other countries.

\section{Conclusions}

The cultural diversity in Malaysia and in the work area of respondents, does not seem to be a big problem for them. This happens because they are more interacting or communicating with their jobs in the project 
alone. Incidentally, there are only 3 (three) Malaysians, the rest are filled by Indonesians and other foreigners, such as from Europe and other Asian countries.

To bridge or reduce the misconceptions that may arise, they will try to understand their culture and interact with them. In addition, the respondents have never experienced cultural shock during their stay in Malaysia, the writer finds out this as actual cultures exist between Indonesia and Malaysia which have many similarities, though many will also find some differences.

\subsection{Additional Result}

In this research, the writer have found side-by-side that communication and interaction barriers are happening more with people or colleagues from Europe, because their work culture is very different from Asian culture, as Mr. D that the Germans are usually arrogant and snobbish.

In this case, it reminds the writer about the high cultural contexts and low cultural contexts learning. Usually Asian people (eastern societies) have a high cultural context, where most of their communication information lies in the physical context or in the individual, little information in the communication is expressed verbally. On the contrary, Europeans (western societies) are in opposition to people in the eastern world, they have a low cultural context where all the information in the communication is clearly stated in the code, hence most verbal information. Therefore, it is important for us to understand their culture in order to improve the effectiveness of communication.

\subsection{Optional Preview}

This research is more focused on intercultural adaptation of Indonesian professional workers in Malaysia, especially adaptation in multicultural work area (environment). In this study, the writer does not review their adaptation (respondents) with people or ethnic groups in Malaysia as well as adaptations in their social environment or socialization world outside the work area.

Therefore, the writer expects that future studies/researches (to be done) on these professional workers will further expand their scope, including the adaptation they make in their socialization field, beyond the work area, and it will be better to study interfaith adaptation in the workplace among Indonesian professional workers working in local companies, such as those working in Proton, MAS, and others, where they will interact more with local workers.

\section{References}

Bandura, A. (1977). Social learning theory. Journal of Group \& Organization Management, 3, 384-385.

Berger, C. R. (1987). Communicating under uncertainly. In M. E. Roloff \& G. R. Mille (Eds.), Interpersonal process: New directions in communication research.

Black, S. J., \& Mendenhall, M. (1990). Cross-cultural training effectiveness: A review and theoretical framework for future research. Academy of Management Review, 15, 113-136.

Dodge, S. (1990). Culture shock and alienation remain problems for many foreign students on U.S. campuses. The Chronicle of Higher Education. A33-36.

Duronto, Patricia M., et.al. (2005). Uncertainty, anxiety, and avoidance in communication with strangers. International Journal of Intercultural Relations, 29, 549-560.

Furnham, A., \& Bochner, S. (1986). Culture shock: Psychological reactions to unfamiliar environments. Retrieved from https://www.cabdirect.org/cabdirect/abstract/19871843911

Gudykunst, W.B. (1988). Uncertainty an anxiety. In Y. Y. Kim \& W. S. Gudykunst (Eds.), Theories in intercultural communication. New York: Sage Publication.

Ismail, N., \& Wok S. (2002). Kursus komunikasi organisasi (Course of organizational communication). PTS Publications \& Distributors Sdn. Bhd., Pahang. 
Kim, Y.Y. (1988). Communication and cross cultural adaptation: An integrative theory.

Knobel, L. (1988). Hewlett-Packard's Cultural Shock. Management Today, 101-106. [Online Unpublished]

Oberg, K. (1954). Culture shock. Indianapolis: Bobbs-Merrill Series in Social Sciences.

Oberg, K. (1960). Culture shock: Adjustments to new cultural environments. Practical Anthropology. 4, 177-182.

Rhinesmith, S. (1985). Bringing home the world. NewYork: Walsh \& Co.

Schwartz, J., \& Exter, T. (1989). All Our Children. American Demographics, 11(5), 34-37

Toffler, A. (1970). Future Shock. Random, New York.

Walton, S. (1990). Stress management training for overseas effectiveness. International Journal of Intercultural Relations. 14, 507-527.

Winkelman, M. (2002). Cultural shock and adaptation. Journal of Counseling \& Development. 73, 121-126. 